Revista de Dialectología y Tradiciones Populares, vol. LXX, n. ${ }^{\circ}$ 2, pp. 299-306, julio-diciembre 2015 ,

ISSN: 0034-7981, eISSN: 1988-8457, doi: $10.3989 /$ rdtp.2015.02.001.04

\title{
La olla a presión: cómo la seguridad fronteriza sigue aumentando el caos
}

\author{
The Pressure Cooker: \\ How Border Security Keeps Increasing the Chaos
}

\author{
Ruben Andersson \\ London School of Economics, UK \\ Departamento de Antropología, Universidad de Estocolmo, Suecia
}

\section{RESUMEN}

Este artículo plantea los problemas y contradicciones del llamado "efecto globo" en los procesos migratorios y la necesidad de partir de una visión global e interconectadas de los flujos poblacionales a través de las fronteras para la elaboración de políticas migratorias justas y efectivas. La revisión de las "crisis" en las fronteras del Mediterráneo, desde las primeras "pateras" que cruzaban Gibraltar hasta la presente "crisis de refugiados", evidencia el hecho de que la presión sobre unas rutas potenciales de entrada no disuade de la voluntad de cruce de frontera sino que desplaza a los emigrantes o refugiados en otras direcciones. Los datos etnográficos muestran cómo por ejemplo el ahora muy elogiado modelo español de gestión de los flujos migratorios en el Mediterráneo no acabó con el problema sino que provocó el desplazamiento de los flujos migratorios hacia caminos más peligrosos en el Sahara y en el norte de África. El problema de España pasó a convertirse en el problema de Italia y, a medida que se desplazaba las rutas, después en el de Grecia, un círculo vicioso que manifiesta el fracaso de las políticas europeas. El autor sigue las historias de personas con las que trabajó etnográficamente, desde Senegal hasta Marruecos, que en sus tránsitos africanos se han visto atrapadas entre vallas, fronteras, dispositivos tecnológicos y mafias de "pasadores". Las experiencias de los inmigrantes señalan un proceso en progresivo aumento: la globalización y mercantilización de las rutas irregulares que emergen paralelamente a los dispositivos migratorios.

Palabras clave: Migración; Fronteras; Refugio; "Efecto globo"; Mercantilización de la irregularidad.

\section{SUMMARY}

This paper explores the problems and contradictions of the so-called "balloon effect" in migratory processes, and the need to elaborate a global and interconnected understanding of population flows 
across borders as the necessary basis to design just and effective migratory policies.The revision of the successive "crisis" in the Mediterranean borders, starting with the first small boats (pateras) which used to cross the Strait of Gibraltar all the way to today's "Refugee Crisis", makes sufficiently clear that the pressure on certain potential migratory entry routes does not discourage the will to cross, but rather forces immigrants and refugees in other directions. Ethnographic data show how, for example, the today prestigious Spanish border control model in Gibraltar did not stop the problem but rather provoked the shiftof migratory flows to more dangerous routes in the Sahara and the North of Africa. Spain's problem eventually became Italy's problem and, in turn, as routes moved East, Greece's problem: a vicious cycle manifesting the failure of European policies. The author follows the life histories of migrants he worked in the route from Senegal to Morocco who, in their respective African transits, have had to face walls, borders, new surveillance technologies and cross-border mafias. Migrants' experiences signal a progressive process: the globalization and commodification of irregular routes, emerging in parallel to migratory inhibition mechanisms.

Key words: Migration; Borders; Refuge; "Balloon Effect"; Commodification of Irregularity.

El aviso del jefe de la Agencia de fronteras exteriores de la Unión Europea, Frontex, pasó casi inadvertido. Estábamos a principios de junio del 2015 y la operación militar en el centro del Mediterráneo, EUNAVFOR-MED, iba a comenzar el 22 de dicho mes: "Si hay una operación militar en las cercanías de Libia esto podría provocar un cambio en las rutas de migración hacia el este " ${ }^{9}$. Una ruta se cierra y otra se abre en otro lugar. Parece obvio pero sin embargo los políticos europeos no están aprendiendo de este hecho tan simple.

Este fenómeno ya es conocido en la fracasada guerra contra la droga como el «efecto globo": se presiona sobre un lugar y el globo se expande hacia otro ${ }^{10}$. Algo similar sucede con los esfuerzos para acabar con la migración irregular, con importantes matices, como se irá viendo.

El efecto globo pone en entredicho el "éxito" de ciertas celebradas operaciones de control migratorio, como las de España. En medio de la "emergencia" de las llegadas en Europa durante este verano dramático de 2015, los líderes del continente, cada vez más desesperados, han mirado hacia las fronteras hispano-africanas para un modelo a seguir en tema de controles. Las llegadas a España registraron de hecho una fuerte caída en los últimos años, lo cual pudiera validar el interés político en los métodos de Madrid. Sin embargo, basta con rascar la superficie de esta respuesta policial para ver las complejas y contraproducentes dinámicas que se esconden tras el supuesto éxito.

El modelo español se basa sobre todo en el elogiado cierre de la ruta marítima entre las Islas Canarias y África Occidental hace casi una década. Después de la "crisis de los cayucos" en el archipiélago turístico en 2006, cuando los medios de comu-

\footnotetext{
${ }_{9}^{9}$ Ver http://migrantsatsea.org/2015/06/05/frontex-director-eu-military-operation-near-libya-mayshift-migration-routes-to-eastern-mediterranean/. EUNAVFOR-MED es el acrónimo en inglés de European Union Naval Force Mediterranean, operación militar para luchar contra los pasadores de migrantes tras las tragedias sufridas por miles de personas en el centro del Mediterráneo. Desde su lanzamiento, la misión ha experimentado una multitud de problemas de carácter legal, político y práctico, como muchos analistas habían advertido.

${ }^{10}$ Sobre el efecto globo, ver informe de LSE IDEAS, Ending the Drug Wars, mayo de 2014. Ver también http://www.coha.org/the-balloon-effect-and-displacement-part-2-of-2/
} 
nicación europeos fomentaron un pánico sobre la migración marítima, España y los países africanos comenzaron a colaborar en deportaciones y en patrullar el Atlántico dentro del marco de una operación conjunta de la entonces recién creada agencia europea Frontex. La operación HERA, liderada por la Guardia Civil, fue calificada como un modelo a seguir —olvidando convenientemente el "efecto globo".

De hecho, esta ruta atlántica desde Mauritania y Senegal hacia las Islas Canarias sólo se había abierto tras el establecimiento de fuertes controles policiales en el norte de Marruecos y en el estrecho de Gibraltar, el reforzamiento en 2005 de las vallas de Ceuta y Melilla y el aumento de las redadas. Como respuesta al "cierre" de la ruta pasando por Marruecos, los barcos empezaron a salir rumbo a Canarias - utilizando puntos de salida cada vez más lejanos a medida que los controles marítimos se iban extendiendo por el litoral africano. Una vez "cerrada" la vía atlántica a través de HERA y las deportaciones masivas, las rutas cambiaron otra vez, ahora hacia los peligrosos caminos a través del Sahara ${ }^{11}$. Así, a mediano plazo, el problema de España se convirtió parcialmente en el problema de Italia, y después en el de Grecia. De esta manera, volviendo a la metáfora del globo, la "presión" aplicada en España hace que las rutas migratorias se desplacen del oeste al este del Mediterráneo. En este contexto, la decisión de Madrid en el verano de 2015 de no aceptar una repartición europea de solicitantes de asilo llegando por Grecia e Italia no sólo indica una falta de solidaridad europea, como se suele escuchar, sino también una falta de responsabilidad por un problema creado, por así decirlo, en común.

El desplazamiento de flujos ya en sí constituye un fracaso a nivel europeo. Aún peor, con cada desplazamiento se crea más peligro y más riesgos, como demuestra la larga travesía desde Senegal hacia las Islas Canarias o la ruta por el Sáhara. Con cada cambio de ruta, además, las redes de pasadores se refuerzan y se profesionalizan, como se ve en los casos de Libia y Turquía recientemente y en menor medida en Marruecos. Cuanto más difícil la travesía, más alto el precio por el servicio de estos "facilitadores" - lo mismo que ha pasado, por ejemplo, en las rutas mexicanas hacia Estados Unidos en las últimas dos décadas. Todo esto genera un círculo vicioso en las fronteras de Europa, donde cada desplazamiento de rutas o cada método nuevo de entrada crea más ímpetu para financiar nuevas patrullas, vallas o dispositivos de vigilancia, y así ad infinitum y ad absurdum.

Los policías y guardias de frontera saben bien cómo funciona ese círculo vicioso, y muchos de ellos me lo explicaron durante mis investigaciones antropológicas. "La migración es una cosa que no se va a parar nunca", me dijo, por ejemplo, un alto cargo de la Guardia Civil, refiriéndose a que las rutas siguen multiplicándose una vez que se cierran las opciones de entrada (incluso las legales) ${ }^{12}$. "Tienes que dejar una vía de escape", me comentó en otra ocasión un policía europeo basado en el Magreb; en caso contrario, advirtió, acabaríamos teniendo un efecto de "olla presión". En 2010,

${ }^{11}$ El número de senegaleses sí bajó en términos absolutos a corto plazo, pero hay que recordar que esto fue relativo a la repentina subida de salidas en 2005-6: de hecho, muchos jóvenes nunca se habían planteado un viaje clandestino a Europa y sólo lo hicieron una vez que la ruta se desplazó desde Marruecos/Sahara Occidental hacia el sur —es decir, gracias en gran parte al "efecto globo".

${ }^{12}$ Cabe notar que, a pesar de tener esta perspectiva, el mismo oficial participaba activamente en el desarrollo de más dispositivos de seguridad, basados en la idea de poder "parar" la migración. 
otro policía me dijo que estábamos en el "ojo del huracán" en cuanto al drama en las fronteras. Esas predicciones se están cumpliendo hoy en Grecia, en los Balcanes y en Italia, donde el cierre de fronteras, frente a la creciente crisis mundial de refugiados, ha creado un "huracán" en las puertas de Europa —o al menos así lo ven los medios y los políticos, a pesar de que la gran mayoría de los refugiados del mundo son hospedados por países en vía de desarrollo, no por Occidente ${ }^{13}$.

Igual que los policías, también los migrantes y refugiados me ayudaron a entender estas realidades absurdas y trágicas de la frontera. Chicos como "Daouda" ${ }^{14}$, por ejemplo, quien conocí en el verano de 2010 en las afueras de Ceuta ${ }^{15}$. Tenía poco más de 20 años y había llegado a Marruecos por la ruta desértica, pasando por Mauritania y el Sahara Occidental. Me contaba cómo le había resultado bastante fácil pasar las fronteras con los papeles en orden gracias a un par de sobornos claves en su camino. Su ambición final podría ser pasar a Europa —él mismo ni lo tenía tan claro, comentó- pero por el momento ejercía felizmente de vendedor ambulante en Tánger, donde vivía con unos amigos senegaleses y guineanos. Un día, sin embargo, Daouda desaparece. Cuando finalmente contacto con él por teléfono, me dice que le habían expulsado a la frontera con Argelia, donde muchos migrantes subsaharianos han sido enviados por las fuerzas de seguridad marroquíes en los últimos años ${ }^{16}$. "Los argelinos cogieron todo mi dinero, todo, todo, todo", es lo único que me dice antes de colgar. Una semana más tarde encuentro a Daouda en Tánger y me cuenta como los marroquíes le llevaron a la "tierra de nadie" de la frontera argelina, de noche. Les indicaron lo que supuestamente era el camino de vuelta a Marruecos, y ahí les dejaron. Daouda y los otros expulsados se pusieron a andar en aquella dirección pero el camino les llevó hacia Argelia. Y allí los soldados argelinos "nos robaron todo, todo...nos preguntaron ¿por qué habéis entrado por aquî́? Y nos dijeron que teníamos que darles todo, que si no nos matarían... Robaron nuestra ropa. Nos dejaron en la ropa interior y hacía mucho frío. Anduvimos descalzos hasta las 8 de la mañana, por el bosque». Daouda consiguió volver a Tánger finalmente y se puso a preparar el viaje hacia España, sobre todo para escaparse de la represión arbitraria que había encontrado en Marruecos.

En ejemplos como el de Daouda — de los que existen cientos y cientos- vemos cómo la colaboración policial euro-africana genera múltiples problemas. Su trato en el país magrebí como "ilegal" (con su sello en el pasaporte expirado por apenas unos días) fue resultado directo de la estrecha cooperación en materia migratoria entre España, Marruecos y en menor medida la UE. Su expulsión irregular a "tierra de nadie" — por una ruta donde ni siquiera había entrado — resultó en violencia y otra "expulsión", esta vez de vuelta a Marruecos, ya que los argelinos no le querían dejar entrar. Finalmente, esta experiencia de pasa-pelota y el incierto limbo de Tánger le empujó a dejar su vida de vendedor ambulante y sus amistades en Marruecos para intentar embarcarse a Europa — contribuyendo así a las ganancias de los pasadores, quienes

\footnotetext{
13 Estadísticas de ACNUR para 2014 muestran que países en vía de desarrollo ahora acogen al 86 por ciento de los refugiados del mundo. Una década antes, esta cifra era del 70 por ciento.

14 Todos los nombres usados aquí son pseudónimos.

15 Como se ve, mis interlocutores suelen ser masculinos por cuestiones de acceso.

${ }^{16}$ Esta práctica se ha interrumpido últimamente.
} 
encontraban en él un cliente idóneo gracias a la represión policial y a la desesperación que genera.

Muchos de los migrantes y ex-viajeros con quienes hablé durante mis investigaciones en Senegal, Mali, Marruecos y España lo tenían bastante claro: para ellos, los controles fronterizos sirven sobre todo como una fuente de ingresos para varios actores, no para "parar" a la migración. En Senegal, por ejemplo, noté en mis investigaciones un resentimiento profundo entre muchos deportados hacia todos los que se habían "beneficiado" de su miseria. En un pueblo pesquero en las afueras de Dakar, hombres como "Mohammadou" habían creado asociaciones de "repatriados" después de su peligrosa travesía hacia las Canarias y su retorno forzado. Mohammadou y otros ex-viajeros como él me hablaron de todos los que se lucraban de la "migración ilegal" (la migration clandestine, en sus palabras, en francés; o mbëkë mi, como se conocía el viaje marítimo en Wolof, que se puede traducir como "golpe de cabeza"). Sentados en las calles arenosas entre las casas de pescadores de su barrio, Mohammadou fumaba sus cigarrillos y me contaba quiénes eran, según él, estos beneficiarios de la lucha contra la migración. Primero, los guardias fronterizos de Europa y sobre todo de países africanos, quienes "recibían dinero" para desviar a migrantes antes de su llegara a las costas de la UE ${ }^{17}$. También sentía rencor hacia las ONGs europeas que entraban en Senegal para lanzar programas de "sensibilización" sobre los riesgos de la travesía —un proyecto bastante inútil. Como se ve en los términos utilizados por referirse al viaje, mbëkë mi o golpe de cabeza, y Barça walla barzakh (Barcelona o el más allá, la muerte), los viajeros conocían los riesgos antes de embarcarse; de hecho, la travesía se presentaba como una manera de mostrar su masculinidad y su bravura frente a la situación sin prospectos y sin gloria en sus barrios natales. Mohammadou se quejó también de periodistas e investigadores como yo que llegábamos a su barrio en búsqueda de historias sobre su mala fortuna. Criticaba duramente a los políticos senegaleses, quienes se lucraban de los fondos españoles de "ayuda al desarrollo" que Senegal y otros países de la región habían recibido en medio de la crisis de los cayucos, en gran parte para convencer a los "Socios" africanos a colaborar en patrullas y en repatriaciones masivas. "Para mi, Frontex es algo que hace la gente para ganarse dinero", me dijo, refiriéndose a las patrullas conjuntas africanas. "Están allí pero si les das dinero, te dejan pasar... ¡esa gente no hace su trabajo!».

Desde la época de la crisis de los cayucos, las rutas utilizadas por africanos del Oeste como Daouda y Mohammadou se han ido desplazando hacia el Sahara. Entre los que llegan a costas italianas procedentes del caos libio, se puede escuchar como ha empeorado la situación en las fronteras euro-africanas desde la crisis de los cayucos. Este verano de 2015, en una visita a Lampedusa y Sicilia, conocí a jóvenes que habían huido de las condiciones espantosas del país. Entre ellos estaba "Songho", un gambiano que había llegado a Libia para trabajar, como muchos otros africanos. "Nunca hubiera querido irme a Italia, pero..." me dijo mostrando una cicatriz causada por un ataque violento y racista en las calles de Trípoli. Ya en la era de Gaddafi, la colaboración del dictador libio con Roma en los controles represivos cambió drásticamente el papel del migrante en Libia: en vez de ser un recurso para un país con gran nece-

${ }^{17}$ La realidad era muchas veces más compleja, involucrando promesas, favores diplomáticos y fondos a nivel estatal. 
sidad de mano de obra, el trabajador africano se empezó a convertir tanto en una buena moneda de cambio en relaciones con Europa como en una fuente de ingresos para bandidos y fuerzas de seguridad. Para Songho era imposible quedarse en Libia en medio del caos y los ataques contra extranjeros. Un policía, cliente de Songho en su oficio de solador, le ayudó a embarcarse por un precio barato - señal de que en Libia, igual que en todos los demás países "colaborando" con Europa en controles, las ganancias de los pasadores se comparte ampliamente con las fuerzas de seguridad. Ahora se encontraba en el limbo en Sicilia sin posibilidad de volver atrás o de continuar hacia adelante, esperando un proceso de asilo que parecía interminable.

Otros viajeros con más recursos van de mano en mano entre pasadores hasta llegar a Europa, evitando así la violencia y el peligro de las calles de Libia. Eso fue el caso de un chico que conocí fuera del centro de "acogida" de Lampedusa, escapándose por la ventana de este recinto cercado para poder ir a la ciudad y llamar a su familia. Aziz era un somalí de 25 años estudiante de informática, y mientras caminaba junto a él me contó su viaje. Aziz hablaba de como los pasadores sudaneses le habían dado buenas cantidades de agua cuando atravesaban el desierto, y como los libios, que luego tomaron las riendas, sólo les dieron una botella para dos días por persona. "Si das algo de agua a un amigo enfermo para beber, entonces morirás tú", dijo Aziz mientras recordaba los cadáveres que había visto esparcidos por las zonas fronterizas, dejados atrás por otros pasadores. Contó como la próxima red, en Trípoli, le había mantenido hacinado en un gran almacén junto a cientos de otros extranjeros. Ese hacinamiento indica que la represión contra los migrantes y refugiados en Libia —evidente también, aunque a menor escala, en Marruecos, Egipto y Argeliaha creado un mercado cautivo donde los "clientes" tienen cada vez menos poder sobre el "producto" (la travesía) que compran. Igual que ha pasado en los últimos años en el Sinaí (fuera de Israel) o en México (dónde centroamericanos son atacados por los cárteles de narcotráfico), los pasadores trataron a Aziz no sólo como cliente sino también como mercancía, intentando extraer dinero de sus familiares bajo amenaza de violencia. "Tienes que convencerles a los pasadores que no tienes una familia rica", dijo Aziz, sonriendo. No quiso decirme cuanto había gastado en su viaje en total - seguramente ni siquiera lo sabía con exactitud.

Las rutas de refugiados de Somalia y del resto del Cuerno de África también son ejemplo de las consecuencias del "efecto globo". Para eritreos y sudaneses, sobre todo, Israel fue durante mucho tiempo un destino principal. A principios del 2013, ese país completó una valla a lo largo de su frontera con Egipto y legisló duramente contra los migrantes. Hasta entonces cerca de 1.000 solicitantes de asilo, principalmente de Eritrea y Sudán, estaban llegando a Israel todos los meses ${ }^{18}$. Después de esas medidas la cifra bajó a casi cero. Mientras tanto Arabia Saudita, otro destino importante, también puso en marcha un dispositivo represivo, construyendo además una valla en la frontera con Yemen. En ese período, la llegada de eritreos y sudaneses a las fronteras de Europa se multiplicaron, desde 2.604 en 2012 a 34.586 en $2014^{19}$.

No vi a muchos sirios en el sur de Italia, por razones parecidas. Hasta aquel mo-

\footnotetext{
${ }^{18}$ Ver http://www.irinnews.org/report/99095/horn-migrants-risk-new-routes-to-reach-europe

19 Cifras de Frontex Annual Risk Analysis 2015, http://frontex.europa.eu/assets/Publications/ Risk_Analysis/Annual_Risk_Analysis_2015.pdf
} 
mento, grandes números de refugiados del conflicto atroz de Siria habían utilizado una ruta compleja y absurda para entrar en la UE: por tierra hasta Estambul, y de allí al norte de África, o incluso a Sudán, para finalmente llegar a las costas de Libia y de ahí embarcarse a Italia. Todo este proceso involucraba grandes ganancias para los pasadores -igual que para los policías fronterizos mirando hacia el otro lado. Pero a principios de julio de este año la advertencia del jefe de Frontex ya se iba cumpliendo: cada vez más sirios (y afganos) habían empezado a utilizar la vieja ruta por Grecia, donde se han venido registrando llegadas récord durante todo el verano de 2015. Las rutas se seguían desplazando, los problemas y los riesgos creciendo, sin ninguna resolución excepto la de siempre: más "seguridad fronteriza" ${ }^{20}$.

Para terminar, hay que notar que el "efecto globo" se extiende ya mucho más allá de las fronteras de Europa. La operación "Sovereign Borders" (Fronteras Soberanas) de Australia ha sido elogiada por su "mano dura", y el primer ministro Tony Abbott ha pedido a Europa que adopte medidas similares para parar a los barcos ${ }^{21}$. Sin tener en cuenta las condiciones especiales, la extrema dureza y el alto coste de esa operación $^{22}$, su "éxito" sigue siendo relativo ya que las nacionalidades de refugiados que llegaban a costas de Australia se solapan con las que llegan a Europa. El país austral recibió 3.500 afganos entre 2012 y 2013, antes de Sovereign Borders y el gran descenso en llegadas que provocó esa operación; mientras tanto, en Europa la cifra de afganos creció de 9.500 a 22.000 en ese mismo período ${ }^{23}$.

En resumen, las rutas irregulares se están globalizando, en paralelo y en respuesta a la globalización de un modelo represivo de "lucha" contra la migración. Este modelo genera riesgos cada vez mayores para los que cruzan las fronteras, sin lograr a disminuir el flujo. Lo que sí que se ha logrado, no obstante, es crear lo que en Illegality, Inc. llamo una "industria de la ilegalidad" (2014). A través de la "emergencia" de la migración y la "lucha" contra la misma, cada vez más sectores tienen ahora un interés en más controles e inversiones en la frontera. Entre ellos se encuentran los sectores identificados por el repatriado Mohammadou — fuerzas de seguridad de Europa y de Africa, gobiernos "Socios" en la "lucha contra la inmigración irregular", y en menor medida ONGs y organizaciones internacionales que proveen servicios en centros de detención y recepción igual que en proyectos de "sensibilización". Allí se encuentra también los sectores de defensa y de "outsourcing", los cuales venden sus productos y servicios a

\footnotetext{
${ }^{20}$ Dado los problemas iniciales de EUNAVFOR-MED, el desplazamiento de rutas para los sirios involucraba otros factores como las políticas represivas contra refugiados sirios en países de primer destino como Egipto.

${ }^{21}$ Por ejemplo, ver http://www.irinnews.org/report/100768/australia-pushes-on-with-asylumseeker-deterrence

22 Australia, al igual que España con Marruecos en relación a África Occidental, ha dependido de vecinos pobres como Papua New Guinea para el éxito de su política de dureza; también ha despertado durísimas críticas por falta de respeto a los derechos humanos. Además, ha surgido acusaciones de que las autoridades australianas han pagado a los pasadores para dar vuelta atrás con su "Cargo": ver http://www.theguardian.com/australia-news/2015/jun/14/united-nations-weighsin-on-outcry-over-reports-australia-paid-people-smugglers. En contraste con el Mediterráneo, no obstante, las llegadas a Australia nunca fueron muy altas y su costa norte es bastante corta permitiendo un cierre parcial o temporal bajo condiciones que simplemente no existen en el sur de Europa.

${ }^{23}$ Cifras de Australia del Dept. of Immigration and Border Protection. Cifras de Europa de Frontex Annual Risk Analysis 2015.
} 
Estados que siguen invirtiendo en más medidas de seguridad, apoyados económicamente por Bruselas. Tenemos que romper ese círculo vicioso: pero con el atrincheramiento de la industria, un cambio de sentido resultará cada vez más difícil.

Si nuestros líderes hablaran en serio cuando dicen que quieren hacer frente a la "crisis" en las fronteras, deberían analizar el problema desde un punto global, utilizando la evidencia que ya existe de los fracasos de las políticas migratorias. Deberían escuchar a los que conocen a fondo la realidad de la frontera - los investigadores, los agentes humanitarios y los guardias fronterizos a pie de calle, y sobre todo, a los migrantes y refugiados. Sin embargo, excepto unas recientes señales positivas de algunas fuerzas políticas, no lo están haciendo. En lugar de una política basada en la evidencia, obtenemos más medidas puntuales y más fondos para el modelo represivo, que en el mejor de los casos consigue trasladar el problema a otro sitio por un tiempo, pero que cada vez más simplemente contribuye a "inflar el globo" —o, utilizando la otra metáfora de este artículo, subiendo la temperatura a la olla presión. El momento ha llegado para un replanteamiento a fondo de la movilidad en la vecindad de Europa y más allá.

\section{BIBLIOGRAFIA CITADA}

Andersson, Ruben. 2014. Illegality, Inc.: Clandestine Migration and the Business of Bordering Europe. Berkeley: University of California Press. 